\title{
Análise do Relacionamento da Cadeia de Suprimentos do Setor de Serviços de Eventos em Goiânia - GO
}

\author{
Relationship Analysis of Supply Chain Services Industry Event in Goiania - GO
}

Análisis de la relación de la cadena de suministro de eventos de la industria en Goiania - GO

Marizangela Gomes Morais ${ }^{1}$

\begin{abstract}
Resumo
Este estudo analisa o relacionamento da cadeia de suprimentos do setor de serviços de eventos em Goiânia - GO, avaliando se esse processo gera valor ao cliente final. Vislumbra-se mercado de eventos como um segmento em plena expansão por sua capacidade de propiciar empregos diretos e indiretos, assim como pelo seu retorno econômico. Contudo o setor é altamente competitivo, exigindo cada vez mais, interação, bem como profissionalismo dos agentes envolvidos. Por ser assim, levantou-se o questionamento "como o relacionamento na cadeia de suprimentos do setor de eventos pode agregar valor ao consumidor final? Utilizouse como bases teóricas as temáticas referentes a cadeia de suprimentos, serviços, marketing de relacionamento e valor. A pesquisa se divide em duas etapas: uma exploratória, outra descritiva de natureza qualitativa. Teve como objeto de estudo duas cadeias de suprimentos do setor de eventos sociais, sendo entrevistados organizadores de eventos, decoradores, buffets, fotógrafos dentre outros. Para tanto utilizou-se dois modelos de mensuração de relacionamento o de Wilson e Vlosky (1997) e Larentis e Slongo (2007) desses selecionou-se atributos os quais originaram o roteiro de entrevista semiestruturado. Os resultados do estudo indicam, de modo geral, uma defasagem existente entre a realidade da cadeia de suprimentos com os conceitos de relacionamento encontrados na literatura, uma vez que a cadeia estudada apresenta algumas lacunas em seus sistemas de atuação.
\end{abstract}

Palavras Chave: Cadeia de Suprimentos, Marketing de relacionamento, serviços, eventos.

\begin{abstract}
Increasingly, companies realize the necessity of interacting with the external environment.

This market trend requires the companies new positions related to the relationship among members of the chain in which they are embedded. Into this approach the marketing supplier

\footnotetext{
${ }^{1}$ Mestre em Adminitração pela Unisinos - RS, Especialista em planejamento turístico pela UFG, Graduada em Adminitração em Turismo pela PUC- GO. Docente dos cursos de graduação e pós graduação do SENAC - GO e Faculdade Cambury. Consultora empresarial e gestora em eventos. Brasil. marizangelaprof@ hotmail.com.
} 
relationships stands out as one of the main operational strategies for the organizations' competitiveness improvement. The aim of this study is to analyze the degree of relationship of the supply chain of the events industry services in Goiania GO evaluating how this process creates value to the final customer. However the industry is highly competitive, requiring more and more interaction and professionalism of the involved agents. The main theories discussed at this study were supply chain, services, relationships, customer value and events. It was used the qualitative research, with a semi structured script to collect data with members of the supply chain of the event industry, considering, event organizer, suppliers and customers. The survey results indicate that, in general, there is a gap between the reality of supply chain of the event industry in Goiania and the concepts of relationship with suppliers studied in the literature, once the relations between chain members is more characterized as transactional exchanges.

Keywords: Supply Chain, Relationship marketing, services, events.

\section{Resumen}

Este estudio analiza el grado de relación de los hechos de la cadena de suministro de la industria de servicios en Goiania - GO, evaluar si este proceso aporta un valor añadido para el cliente. Vislumbra el mercados de los eventos como un segmento de ampliación de su capacidad para proporcionar puestos de trabajo directos e indirectos, así como su rendimiento económico. Sin embargo, la industria es muy competitiva, cada vez más exigente, la interacción y la profesionalidad de los implicados. Entonces surge, así como la pregunta del problema "como la relación de los eventos de la industria de cadena de suministro pueden agregar valor al consumidor final? Fue utilizado como las cuestiones teóricas el temático relacionados la cadena de suministro, de servicios, marketing relacional y el valor del cliente. La investigación se dividió en dos etapas, un cualitativo y otro exploratorio descriptivo. Teniendo en cuenta que es un estudio de casos múltiples. Se utilizaron dos modelos de investigación y de la medición de la relación: Vlosky y Wilson (1997) y sus consignas y Larentis (2007) en el que fueram seleccionados atributos que dieron origen al guión de la entrevista semi-estructuradas con dos cadenas de suministro industria de los eventos. los miembros entrevistados fueram organizador del evento, los proveedores y clientes. Los resultados del estudio indican, en general, una brecha entre la realidad de la cadena de suministro del sector de los eventos en Goiania con los conceptos de relación estudiados en la literatura.

Palabras clave: acontecimientos, lãs relaciones, cadena de suministro

\section{Introdução}

A crescente concorrência, tanto em quantidade quanto em valor agregado, exige que as empresas desenvolvam ações de intimidade com seus fornecedores e clientes, se almejam continuar competitivos no mercado. Em face desse cenário, as empresas buscam o foco nas 
necessidades de seus parceiros usando, entre outras estratégias, os relacionamentos de longo prazo com seus clientes e fornecedores. Entretanto, a efetiva possibilidade de concretização dessas alianças com os clientes depende da capacidade da empresa em integrar as competências de seus fornecedores para de fato gerar valor ao cliente final da cadeia (SLACK 2002).

O principal objetivo deste estudo é analisar o relacionamento da cadeia de suprimentos do setor de serviços de eventos em Goiânia - GO, avaliando se esse processo gera valor ao cliente final. Para atingir o objetivo proposto foram estudados temas relacionados à cadeia de suprimentos, serviços, relacionamentos, valor para o cliente. Essas teorias sustentam o estudo propiciando subsídios para o questionamento que circunda essa pesquisa. Como o relacionamento na cadeia de suprimentos do setor de eventos pode agregar valor ao consumidor final?

Cada vez mais as empresas percebem a necessidade de interagir com o ambiente externo. Essa tendência exige delas novos posicionamentos em relação ao relacionamento com os membros da cadeia na qual estão inseridas explana Ochi (2004). Atualmente o cliente tem acesso a informações de todos os processos pelos quais passam os produtos consumidos por ele, portanto quanto mais unificado, informado e leal forem os membros de um canal, mais forte ele será perante o cliente (ZEITHAML, BITNER, 2003).

De acordo com Rocha e Luce (2006, p.88) os estudos sobre marketing de relacionamento podem ser classificados em duas subáreas: "o relacionamento entre organizações e clientes individuais, e o relacionamento entre organizações", incluídos nesse último tanto o relacionamento entre membros de canais de distribuição quanto o relacionamento entre empresas no marketing business-to-business. O presente estudo destaca a segunda subárea o relacionamento entre organizações, entre membros de canais, ele foi ressaltado por apresentar relevância no setor objeto de estudo, pois o segmento de eventos é composto pela administração dos vários recursos inerentes ao acontecimento, os quais são contratados anteriormente pelo cliente. Os diversos fornecedores são: decoração, buffet, fotografia, cenário, sonorização, hotéis, transporte, receptivo, dentre outros. Além disso, compreendem segmentos independentes em sua função e interdependentes em sua execução (MARTIN, 2003). O setor de eventos estudados encontra-se na cidade de Goiânia - GO. 
Goiânia foi fundada em 1935 e conta com 1,2 milhões de habitantes, tendo como base econômica o comércio, os serviços, as indústrias de alimentação e as confecções. Nos últimos anos, um novo foco de desenvolvimento surge para alavancar ainda mais a economia local, o setor do turismo de eventos científicos e sociais, isso culmina na abertura de inúmeras empresas desse segmento.

De acordo a International Congress and Convention Assocition (ICCA) os turistas participantes de congressos, convenções (eventos científicos) têm uma despesa média três vezes superior a de um turista comum. O Brasil subiu duas posições, chegando ao sétimo lugar no ranking dos países que mais sediaram eventos no mundo em 2011. A informação consta no relatório anual da Associação Internacional de Congressos e Convenções (ICCA ) O documento revela também que subiu de 48 para 57 o número de cidades brasileiras que receberam congressos e convenções no ano passado. Soma-se a essa realidade outro dado, o turismo é o terceiro setor mais lucrativo da economia mundial. Além de sua importância econômica, a realização de eventos tem importância significativa para as cidades em geral, pois eles geram empregos diretos e indiretos, divulgam a cidade sede do acontecimento, reduz a sazonalidade abastecendo a infraestrutura durante a baixa estação, transforma a cidade sede em polo de debates técnicos/científicos ou sociais, geralmente com foco na mídia, favorece os habitantes da cidade sede com melhores condições para reciclagem profissional.

O estudo do relacionamento entre os membros da cadeia de suprimentos do setor de eventos visa o crescimento dessa área em Goiânia, pois segundo a Associação Brasileira dos Organizadores de Eventos (ABOC), essa cidade está em $6^{\circ}$ lugar entre as mais procuradas para a realização de eventos.

O presente artigo se divide em etapas. A primeira elucida o entendimento inicial composto por introdução, pergunta problema e objetivos. Na segunda apresenta-se a fundamentação teórica a qual aborda-se temas relevantes para o estudo. A terceira sessão compõe-se pela metodologia, nela contém os métodos utilizados na pesquisa. Essa se trata de um estudo de casos múltiplos, tipo exploratória, de natureza qualitativa, tendo como unidade de análise duas cadeias de suprimentos do setor de eventos. Os pesquisados são organizadores de eventos, fornecedores do segmento de eventos sociais, clientes contratantes e clientes participantes. Ressalta-se que neste estudo denominam clientes contratantes aqueles que contratam os 
serviços para realizar o evento idealizado por eles, como o anfitrião. Já as pessoas convidadas para participar dos eventos foram denominados clientes participantes.

A quarta sessão compõe-se por dados e análise da pesquisa, os relatos levantados por meio da entrevista, bem como o cruzamento entre as contribuições teóricas.

\section{Marketing de Relacionamento}

Assegura Ochi (2004, p.30) que, "o marketing de relacionamento procura servir-se de uma interação direta e do aprendizado com o cliente para agregar o valor que ele deseja ou espera, partilhando os benefícios mútuos gerados por meio de um relacionamento permanente".

Claro (2004) ressalta que com o amadurecimento do conceito de marketing, gestores e acadêmicos começaram a vislumbrar a importância do marketing de relacionamento. Há vários fatores que levaram esse tema ao centro das atenções, como: a propagação dos sistemas de informação, expansão do setor de serviços, mudança na natureza da competição, satisfação do cliente ao longo termo e a formação de rede de negócios.

Dentre os fatores citados acima se destaca a expansão do setor de serviços, no qual Claro (2004) ressalta que com a expansão dos serviços, profissionais de marketing começaram a prestar mais atenção ao lado soft da interação com seus clientes. Muitas empresas perceberam que ter um excelente produto, processos impecáveis e o melhor preço não são o suficiente. Isso porque talvez grande parte das decisões dos clientes em continuar a lidar com uma empresa é relacionada ao fato de como eles são tratados ou como se sentem realizando negócios com ela. Com o avanço em serviços, os profissionais responsáveis por relacionamentos puderam desenvolver uma visão holística de como o marketing contribui para se atingir a satisfação dos clientes na plenitude do termo. As citações acima se direcionam ao relacionamento $\mathrm{B} 2 \mathrm{C}$, no qual se destacam a relação entre empresa e cliente. Ferreira \& Sganzerlla (2000) destacam que o Marketing de relacionamento se apoia na interação existente em todos os serviços prestados aos clientes. Um meio de relacionamento entre a produção e o consumo deve promover a interação, para que, após a entrega de um produto ou serviço, novas vendas sejam viabilizadas. Por isso trona-se importante a interatividade entre "empresa e empresa" e "empresa e cliente". 
Durante algum tempo, o marketing de relacionamento foi considerado uma abordagem que se referia apenas às relações entre comprador e vendedor, por meio da qual uma organização buscaria estabelecer, fortalecer, desenvolver relações de longo prazo com clientes potenciais e atuais. Entretanto, mais recentemente, alerta-se para outros relacionamentos relevantes à oferta de valor aos clientes. Baseado nessa visão mais ampla, comungada por Vavra (1993), Bretzke (2000) e Berry (1995), o Marketing de relacionamento deve considerar todos os relacionamentos que possam influenciar a satisfação do cliente, tais como: Relacionamento com fornecedores de bens e serviços; Relacionamentos laterais (concorrência, organizações não lucrativas, governo, sindicatos, vizinhança); Relacionamentos internos (unidade de negócios, áreas funcionais, empregados); Relacionamentos com compradores. A visão desses autores apresenta o relacionamento B2B, a qual destaca a relação entre empresas, reforçando assim a intenção da pesquisa em estudar o marketing de relacionamento entre os membros da cadeia de suprimentos do setor de serviços, ou seja, entre empresas parceiras.

Apresenta Claro (2004) mais uma vertente do marketing de relações, a qual reforça a importância das empresas saberem diferenciar relacionamento de transação, pois assim as organizações entenderão que clientes e parceiros são ativos de longo prazo. Caso adotem uma atitude de construção de relacionamentos e não de transação, os resultados tornam-se mais duradouros e eficientes. Existem várias diferenças entre transação e relacionamento onde transação caracteriza-se pelo contato impessoal, clima suspeito, informações vagas e dispersas, baixa confiança entre as partes, força voltadas mais para o preço, baixo investimento no contato. Já o relacionamento caracteriza-se pelo contato bilateral, clima colaborativo, aberto, informações compartilhadas, flexibilidade na resolução de problemas, planejamento conjunto, confiança alta.

Para que o Marketing de Relacionamento tenha êxito na implantação dentro das empresas, Madruga (2004) apresenta o desenvolvimento de seis funções essenciais no processo: 1. Elaboração conjunta de nova visão e cultura empresarial voltada para os clientes e parceiros. 2. Construção de objetivos de marketing de relacionamento conectados à visão e sempre de natureza límpida. 3. Estabelecimento das estratégias de marketing de relacionamento voltadas para a criação de valores em conjunto com os clientes. 4. Implementação de ações táticas com o foco no relacionamento colaborativo com clientes. 5. Obtenção de benefícios mútuos. 6 . 
Direção da ação, capacitação e envolvimento dos colaboradores da empresa para relacionamentos superiores.

Aponta Ganesan (1994) dois fatores fundamentais os quais direcionam a relação, entre empresas: a dependência mútua e a confiança entre as partes envolvidas. Esse autor considera confiança como a vontade que uma das partes possui em acreditar nas atitudes do parceiro perante o processo de troca. E dependência é a necessidade que uma das partes tem em manter a relação com a outra para alcançar metas desejadas.

Os autores Sheth e Parvatiyar (apud SLONGO; LIBERALI, 2004) afirmam que gerenciar serviços está no centro da construção e manutenção de relacionamentos, ainda que o marketing de relacionamentos esteja baseado também em outros aspectos, como: a construção de redes, o estabelecimento de acordo com alianças, parcerias estratégicas e compromisso. Compreende-se então que o serviço faz parte de toda relação entre empresa e consumidor, pois se há produtos, há serviços e, naturalmente, relacionamento.

\subsection{Modelos de mensuração de relacionamento na cadeia de suprimentos}

Destaca-se neste estudo dois modelos que apresentam relevância no que tange a mensuração de marketing de relacionamento, pois influenciaram diversos trabalhos no Brasil: o modelo de Wilson e Vlosky (1997) e o modelo apresentado por Larentis e Slongo (2008). Os dois modelos foram escolhidos por terem sido utilizados em inúmeros estudos que abordam relacionamento no setor de serviços. Wilson e Vlosky (1997) desenvolveram, após uma extensa revisão de diversos autores, um modelo com seis grandes atributos que, podem ser utilizado para relacionamento B2B. Ele é composto por: dependência do fornecedor; nível de comparação com fornecedores alternativos; investimento no relacionamento; troca de informações; confiança e comprometimento. Como apresenta a figura 1. 


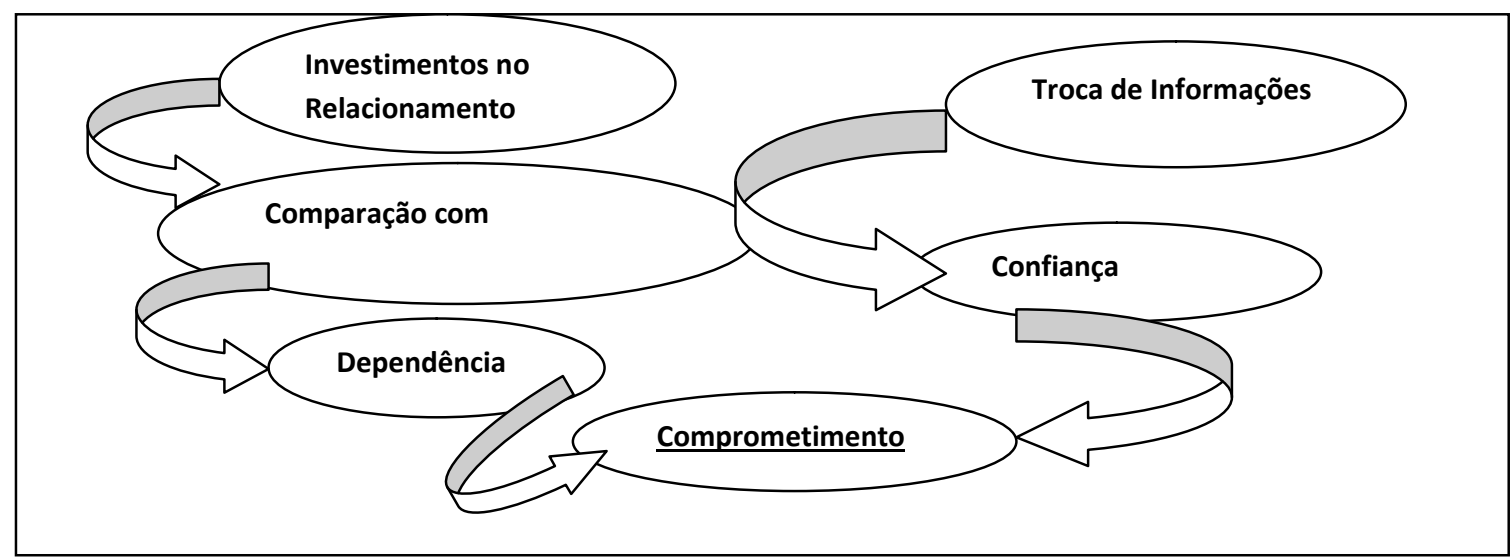

Figura 1 - Modelo de marketing de relacionamento de Wilson e Vlosky.

Fonte: Adaptação de Wilson, E. \& Vlosky, R. (1997).

O outro modelo apresentado por Larentis e Slongo (2007) teve como objetivo verificar as influências do relacionamento entre fabricantes e intermediários na construção e na manutenção de vantagens competitivas sustentáveis. Os construtos considerados para a definição das hipóteses e para a formulação do modelo teórico são benefícios econômicos do relacionamento, compatibilidade de valores, investimentos de recursos no relacionamento, na confiança, no comprometimento e na cooperação. Como apresentado na figura 2.

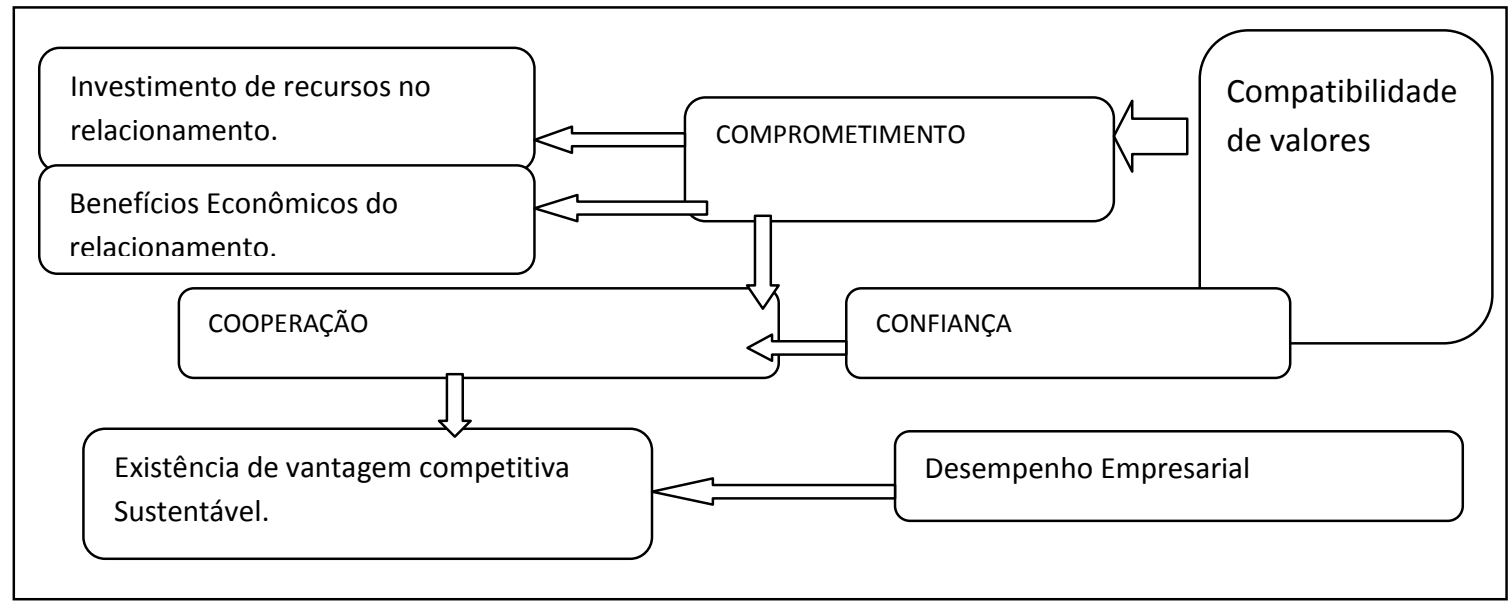

Figura 2 - Modelo teórico proposto por Larentis e Slongo

Fonte: Adaptação de (LARENTIS; SLONGO, 2008) 
Os modelos apresentados, bem como o referencial teórico serviram de base para a criação de categorias de análise para estudar o setor de eventos. Após a análise das categorias acima, foram selecionadas as que aparecem com mais frequência, tanto nos modelos quanto no aporte teórico, a fim de verificar como foram mesuradas, para que então pudessem ser definidos os questionamentos os quais permearam a presente pesquisa.

\section{Cadeia de Suprimentos}

Pires (2004) descreve cadeia de suprimento como uma rede de companhias autônomas, ou semiautônomas, que são efetivamente responsáveis pela obtenção, produção liberação de um determinado produto e/ou serviço ao cliente final. Para Bititci et al. (2005) cadeia de suprimento é uma cadeia de empresas individuais, composta pela relação entre clientes e fornecedores, que opera como uma empresa individual que tenta maximizar seus próprios objetivos e, dessa forma, sub-otimizando o desempenho total. Os autores Pires (2004) e Bititci et al. (2005), compartilham ideias semelhantes em relação à cadeia de suprimentos, pontos de vista que representam com clareza a cadeia de suprimentos estudada no presente estudo.

Slack (2002) estabelece o conceito de cadeia de suprimentos, e define que ela trata o fluxo de materiais, o fluxo de informações como também o fluxo financeiro de uma forma global, integrando as cadeias produtivas dos fornecedores, da empresa, dos clientes, em alguns casos dos fornecedores dos fornecedores e dos clientes dos clientes.

O objetivo principal de um estreitamento das relações com fornecedores constitui-se em criar um relacionamento para garantir que o produto e ou serviço satisfaça às necessidades de adequação ao uso com um mínimo de inspeção de recebimento e ação corretiva (JURAN, 1992). O autor ainda elege uma série de atividades que devem ser seguidas visando o relacionamento cliente-fornecedor, são elas: o planejamento pré-contrato, a avaliação da aptidão do fornecedor, a seleção do fornecedor, o custo total de uma compra, planejamento conjunto e cooperação com fornecedor durante a execução de contrato. 
Discorrem Fleury e Fleury (2003, p. 129) que, "Uma das principais características da nova economia é a transição da eficiência individual para a eficiência coletiva". A competitividade é e será cada vez mais relacionada ao desempenho de redes interorganizacionais e não de empresas isoladas. Por isso gerenciar a cadeia de suprimentos consiste em gerenciar os processos que envolvem os parceiros ao longo do canal, no sentido de gerar valor para o cliente e seus stakeholders.

Além disso, "nenhuma operação produtiva ou parte dela existe isoladamente, ou seja, todas as operações fazem parte de uma rede maior, interconectada com outras operações" (SLACK; CHAMBERS; OHNSTON, 2002, p.25). Essa rede inclui os fornecedores e os clientes, ou seja, trata-se do conceito de gerenciamento da cadeia de suprimentos - Supply Chain Management (SCM). O gerenciamento da cadeia de suprimentos (SCM) pressupõe, fundamentalmente que, as empresas devem definir suas estratégias competitivas e funcionais por meio de posicionamentos (como fornecedores e como clientes) nas cadeias produtivas em que se inserem (PIRES, 2004). De maneira geral, a SCM busca intensificar, somar e amplificar os benefícios de uma gestão integrada da cadeia de suprimentos. Assim, as estratégias e as decisões deixam de ser formuladas, firmadas sob a perspectiva de uma única empresa, passando a fazer parte da cadeia produtiva como um todo.

Segundo Mentzer et al. (2001), para que possa ser implementada a gestão da cadeia de suprimentos é necessária a existência de uma filosofia compartilhada por todas as empresas constituintes, compreendendo um conjunto de valores, crenças e ferramentas que permitam o reconhecimento das implicações sistêmicas e estratégicas das atividades envolvidas na administração dos fluxos compreendidos (MENTZER et al, 2001; COUGHLAN et al, 2002).

Vale destacar que o sucesso do gerenciamento da cadeia de suprimentos também se deve ao comando da cadeia. Esse comando significa orientar, conduzir constantemente mudanças no planejamento, na administração do canal, a fim de alinhá-lo às necessidades dos clientes e ao mesmo tempo otimizar lucros de todos os parceiros (RANGAN, 2008). 


\section{Serviços}

Um serviço é definido como uma forma de proporcionar tantas satisfações quantas forem possíveis pela posse do bem ou do serviço adquirido. Ele consiste sobretudo, em uma forma de ampliar um produto vendido. O serviço pode ser um fator chave de sucesso ou, ao contrário, um fator crítico de fracasso estratégico (ALBRECHT, K. \& BRADFORD 1992; COBRA \& RANGEL apud CARDOSO, 1995; HESKETT et al., 1997; GIANESI \& CORRÊA, 1996; SLONGO, 2004). Em geral, os autores citados definem serviços como a oferta consistente de utilidade de tempo e lugar. Entretanto outras concepções os associam ao produto do sistema logístico de uma empresa, bem como à distribuição de seu composto de marketing. Por outro lado, descreve-se o caráter eminentemente estratégico, cujo papel é o de agregar valor ao uso, isso significa que o produto ganha maior valor aos olhos do cliente na medida em que o serviço adiciona valor ao produto em si (ALBRECHT, 1992).

Gronroos (1991, p. 27) define serviços como uma "atividade ou uma série de atividades de natureza mais ou menos intangível que normalmente, mas não necessariamente, ocorre em interações entre consumidores e empregados de serviços, recursos físicos ou bens", sistemas do fornecedor de serviço, que são oferecidos como soluções para os problemas do consumidor. Ponderam Zeithaml e Bitner (2003), que os serviços são atuações, em geral desempenhadas por seres humanos, por isso dois serviços nunca serão exatamente desempenhados de forma igual. Em consequência disso a qualidade deles depende das pessoas que os prestam e consomem. Dessa forma o segredo consiste em conseguir qualidade, respeitando-se a variabilidade, estabelecer padrões mínimos que garantam uma performance adequada ao serviço, pois o difícil não é ser excelente um dia, mas conservar a excelência todos os dias.

Daí a importância de se estabelecer padrões mínimos que garantam o sucesso, como descrito por Zeithaml e Bitner (2003). Mas para que isso ocorra é necessário uma qualidade no relacionamento entre todos os envolvidos no serviço, devido à dependência do elemento humano e por ser perecível e intangível.

Vargo e Lusch (2006) apresentam três características sobre o setor de serviços: $1^{\circ}$ as mercadorias são mecanismos de prestação de serviços. $2^{\circ}$ cultura do consumo. $3^{\circ}$ a definição 
do próprio serviço (VARGO; LUSCH, 2006, p. 4), pois “as pessoas não compram objetos, mas compram performances". Infere-se pelo argumento dos autores Heskett, Vargo e Lusch (2006) que, para gerar um serviço de qualidade ou agregar valor a um produto ou mesmo serviço, é necessário se interagir com o cliente, saber suas expectativas. Mas essa interação depende da satisfação e da lealdade, não só dos clientes, mas de toda cadeia. Isso demonstra a importância do relacionamento entre todos os envolvidos no setor.

O envolvimento entre empresas e clientes pode ser explicado pelas características descritas sobre o setor de serviços: Intangibilidade, inseparabilidade, variabilidade, perecibilidade. Para Zeithaml; Bitner (2003) Esses fatores unidos propiciam ao cliente formar sua opinião em relação à empresa com mais facilidade em função do relacionamento direto que acaba mantendo com ela. Essa análise permite verificar o porquê de Gronroos (1991) apontar o marketing de Relacionamento como a estratégia mais adequada para empresas de serviços.

\subsection{Valor para o cliente}

O valor percebido é uma construção multimensional derivada das percepções de preço, qualidade, quantidade, benefícios, sacrifícios cujas dimensões devem ser analisadas e estabelecidas para cada categoria de produto (SINHA; DE SARBO, 1998). Entender o que efetivamente é importante nesse processo possibilita as empresas atenderem melhor as necessidades e desejos de seus clientes, aumentando o valor disponível e obtendo vantagem competitiva por terem possibilidade de desenvolver um melhor relacionamento com seu cliente. Segundo Hamel e Prahalad (1990), deve-se ir além de simplesmente perguntar aos clientes/usuários o que eles desejam, deve-se explorar: necessidades declaradas; necessidades reais; necessidades não declaradas; necessidades de "algo mais"; necessidades "secretas".

De acordo com Porter (1989), os fornecedores possuem cadeias de valores que, pela execução de suas atividades, agregam valor e custos ao produto. Dessa forma, os fornecedores podem influenciar o desempenho das empresas. Por outro lado, o produto passa ainda pelas cadeias de valores do canal, cujos integrantes, por sua vez, podem executar outras atividades nos produtos, agregar valor e custo a eles, além de afetar o comprador e a própria empresa.

Esclarece Zeithaml (1998), que podem existir diferenças entre as expectativas dos clientes quanto aos atributos de valor do produto e as percepções da empresa sobre essas expectativas, 
isso corresponde a um gap entre o que a empresa entende que o cliente quer (visão interna) e o que o cliente diz querer (visão externa) em termos de atributos de valor. A empresa deve identificar a visão externa, comunicar a sua estrutura (reduzindo o eventual gap) e adotar estratégias de marketing (abrangendo o composto de produto, a escolha de segmentos-alvo e o posicionamento) as quais agreguem valor aos seus produtos ou serviços. $\mathrm{O}$ valor percebido pelo cliente é resultado do valor agregado ao longo de toda a cadeia de suprimento.

\section{Método}

A presente pesquisa baseia-se em reunir informações detalhadas sobre uma unidade de análise, a cadeia de suprimentos do setor de eventos, tendo como objeto de pesquisa duas cadeias com perfil distinto, portanto um estudo de casos múltiplos. Para tanto utiliza-se como instrumentos de coleta de dados a entrevista e a observação caracterizando uma pesquisa qualitativa.

Diante dos relatos da entrevista, em que os organizadores de eventos definem quem são os membros da cadeia, selecionou-se os membros da cadeia que são considerados primordiais na execução. Sendo: o organizador de eventos também conhecido no segmento de eventos sociais, como: cerimonialista, empresa de decoração, empresa de Buffet, empresa de som, empresa de filmagem, fotografia, locação de espaço para festa e mesa de bolo chamada no presente trabalho de cadeia principal.

Optou-se então por estudar duas cadeias com perfil distinto, sendo uma o organizador de eventos com mais tempo de mercado. Considera-se esse publico, o profissional com mais de 5 anos de atuação, trabalhando com pessoas de classe média alta e classe A. E outra cadeia, com o organizador com no máximo 2 anos de atuação, atuante na classe $\mathrm{C}$ e classe média baixa. Buscou-se também um evento de cada organizador para efetuar o restante da pesquisa, ressalta-se que ambos optaram pelo evento social casamento, por ser mais comum e se realizar praticamente todos os finais de semana. Dentro de cada evento foram pesquisados os fornecedores, os clientes contratantes (noivos) e convidados, denominados no presente trabalho de clientes participantes. Após a pesquisa nos eventos, também se realizou uma entrevista com alguns membros da cadeia de suprimentos de cada fornecedor, são os 
fornecedores de matéria-prima dos fornecedores de eventos, chamados no presente estudo de cadeia secundária. Obtendo assim, um total de 25 entrevistados. O quadro 1 apresenta os sujeitos de pesquisa.

Quadro1: Sujeitos da pesquisa

\begin{tabular}{|c|c|c|c|c|c|}
\hline $\begin{array}{l}\text { Quesito tempo } \\
\text { de atuação }\end{array}$ & Organizador & Fornecedores & $\begin{array}{l}\text { (cadeia } \\
\text { secundária) }\end{array}$ & $\begin{array}{l}\text { Cliente } \\
\text { contratante }\end{array}$ & $\begin{array}{l}\text { Cliente } \\
\text { participante }\end{array}$ \\
\hline $\begin{array}{l}\text { Mais de } 5 \text { anos } \\
\text { de atuação }\end{array}$ & $\begin{array}{l}1 \\
\text { Entrevistado }\end{array}$ & $\begin{array}{l}5 \\
\text { Entrevistados }\end{array}$ & 3 & $\begin{array}{l}1 \\
\text { entrevistado }\end{array}$ & $\begin{array}{l}4 \\
\text { Entrevistados }\end{array}$ \\
\hline $\begin{array}{l}\text { Máximo de } 2 \\
\text { anos de atuação }\end{array}$ & $\begin{array}{l}1 \\
\text { Entrevistado }\end{array}$ & $\begin{array}{l}5 \\
\text { Entrevistados }\end{array}$ & & $\begin{array}{l}1 \\
\text { entrevistado }\end{array}$ & $\begin{array}{l}4 \\
\text { Entrevistados }\end{array}$ \\
\hline $\begin{array}{l}\text { Total de } \\
\text { empresas } \\
\text { pesquisadas }\end{array}$ & $\begin{array}{l}2 \\
\text { Organizadores }\end{array}$ & $\begin{array}{l}10 \\
\text { Fornecedores }\end{array}$ & $\begin{array}{l}3 \\
\text { Entrevistados }\end{array}$ & $\begin{array}{l}2 \\
\text { clientes } \\
\text { contratantes }\end{array}$ & $\begin{array}{l}8 \\
\text { clientes } \\
\text { participantes }\end{array}$ \\
\hline
\end{tabular}

Total de 25 ( vinte e cinco) entrevistados

Fonte: elaborado pela autora

Os entrevistados foram escolhidos por sua importância para o evento social, assim como sua relação com o cliente contratante, antes, durante e após o evento. Como apresenta o quadro 2.

Quadro 2: relação dos sujeitos de pesquisa clientes e fornecedores.

\begin{tabular}{|l|l|}
\hline \multicolumn{2}{|l|}{ Relação cliente contratante e cliente participante com fornecedores } \\
\hline $\begin{array}{l}\text { Membros da cadeia } \\
\text { de suprimentos }\end{array}$ & Relação \\
\hline $\begin{array}{l}\text { Organizador de } \\
\text { eventos }\end{array}$ & $\begin{array}{l}\text { Planeja o evento juntamente com o cliente contratante. Sendo responsável pela } \\
\text { montagem e execução do evento. Tem contato no pré, trans e pós evento. }\end{array}$ \\
\hline Decoração & $\begin{array}{l}\text { Cliente contratante escolhe com antecedência a decoração. Mas não participa do } \\
\text { processo de montagem, pois isso é função do organizador. O cliente participante } \\
\text { tem contato com a decoração apenas quando o evento se inicia. Contato maior } \\
\text { pré-evento e durante. }\end{array}$ \\
\hline Fotos e filmagem & $\begin{array}{l}\text { O cliente participa da primeira parte do serviço, onde são tiradas as fotos e } \\
\text { somente após o evento as fotos são entregues. Contato maior trans-evento } \\
\text { (durante) }\end{array}$ \\
\hline
\end{tabular}




\begin{tabular}{|l|l|}
\hline Som e iluminação & $\begin{array}{l}\text { Tanto o cliente contratante quanto o participante não acompanham o processo } \\
\text { de montagem do som. Apenas tem contato no momento do evento. Contato pré } \\
\text { e trans evento. }\end{array}$ \\
\hline Espaço para festa & $\begin{array}{l}\text { O cliente contratante participa da escolha do local do evento, mas não participa } \\
\text { da montagem e organização do local para a realização do evento. Geralmente os } \\
\text { dois clientes contratante e participante chegam ao local na hora do evento. Pré e } \\
\text { trans evento. }\end{array}$ \\
\hline Buffet & $\begin{array}{l}\text { Clientes não participam da preparação dos alimentos e bebidas. O contato é } \\
\text { efetivado no momento em que degusta o que é servido durante o evento. Pré e } \\
\text { trans-evento. }\end{array}$ \\
\hline Mesa de bolo & $\begin{array}{l}\text { Cliente contratante escolhe os doces e bolo antes do evento. No dia do } \\
\text { acontecimento não acompanha a montagem. Tem contato com a mesa de doces } \\
\text { apenas na hora em que o evento esta acontecendo. Contato pré e trans-evento. }\end{array}$ \\
\hline
\end{tabular}

Fonte: autora.

\subsection{Procedimentos para coleta de dados}

Utilizou-se na pesquisa um roteiro semiestruturado, elaborado com base nos modelos de mensuração de marketing de relacionamento, apresentados na fundamentação teórica. Os modelos de Wilson e Vlosky (1997), bem como o de Larentis e Slongo (2007) serviram de base para a identificação de categorias de análise para estudar o relacionamento na cadeia de suprimentos do setor de eventos. Selecionou-se as categorias que aparecem com mais frequência tanto nos dois modelos como no referencial teórico. O quadro 3 apresenta como as categorias foram avaliadas pelos autores.

\section{Quadro 3: Categorias utilizadas para elaboração de roteiro para entrevista com organizadores e fornecedores.}

\section{CATEGORIA COMPROMETIMENTO}

MODELO WILSON E VLOSKY (1997)

O comprometimento é avaliado neste modelo pelo tempo em que as empresas trabalham juntas, as parcerias realizadas, bem com a disposição e esforço por um relacionamento melhor.

\section{MODELO LARENTIS E SLONGO (2007)}

O comprometimento é avaliado neste modelo pelo relacionamento mais duradouro, parcerias, investimento, esforço para um relacionamento melhor e aumento das compras. 


\section{CATEGORIA CONFIANÇA \\ MODELO WILSON E VLOSKY (1997) \\ A confiança é avaliada neste modelo pela \\ preocupação com os interesses dos parceiros, \\ respeito pelas confidencialidades de informações, merecimento, menos trabalho com supervisão.}

MODELO LARENTIS E SLONGO (2007)

Confidencialidade e veracidade de informações bem como merecimento.

\section{CATEGORIA TROCA DE INFORMAÇÕES}

\begin{tabular}{|l|l|}
\hline MODELO WILSON E VLOSKY (1997) & MODELO LARENTIS E SLONGO (2007) \\
\hline $\begin{array}{l}\text { Existência e ausência de troca de informações entre } \\
\text { fornecedores. }\end{array}$ & O modelo não utilizou esta categoria. \\
\hline
\end{tabular}

\section{CATEGORIA DEPENDÊNCIA DO FORNECEDOR}

MODELO WILSON E VLOSKY (1997)
A dependência é avaliada neste modelo pelo grau de
dependência do fornecedor, importância do
fornecedor, possibilidade de substituição do
fornecedor e equilíbrio de parceria.

\section{CATEGORIA INVESTIMENTO NO RELACIONAMENTO}

\begin{tabular}{|l|l|}
\hline MODELO WILSON E VLOSKY (1997) & MODELO LARENTIS E SLONGO (2007) \\
\hline $\begin{array}{l}\text { O investimento no relacionamento é avaliado neste } \\
\text { modelo pelos transtornos com o encerramento do } \\
\text { relacionamento comercial e as estratégias investidas } \\
\text { em prol da implantação de parceria. }\end{array}$ & $\begin{array}{l}\text { O investimento no relacionamento é avaliado neste } \\
\text { relacionamento comelos transtornos com o encerramento do } \\
\text { prol da implantação de parceria. }\end{array}$ \\
\hline
\end{tabular}

Fonte: autora

\section{Análise da Pesquisa Realizada com os Organizadores de Eventos e Fornecedores}

Pelos dados coletados em entrevista percebe-se tanto na cadeia 1 quanto na cadeia 2 que para se realizar um evento são necessárias inúmeras empresas, em sua maioria autônomas, dessa 
forma cada uma delas torna-se responsável por uma parte do processo de construção do produto final, ou seja, o evento. A empresa de decoração cuida da ornamentação do evento, enquanto a empresa de buffet organiza a parte de alimentos e bebidas. A empresa de mesa de bolo monta os doces ao passo que a de som monta a pista de dança, todos trabalhando em prol de um mesmo produto e do mesmo cliente. Observa-se então que o segmento de eventos se enquadra no contexto de cadeia de suprimentos descrito por Pires (2004), no qual ele conceitua essa cadeia de suprimentos como uma rede de companhias autônomas ou semiautônomas, efetivamente responsáveis pela obtenção, produção, liberação de um determinado produto e/ou serviço ao cliente final.

Na cadeia de suprimentos 1 quanto a comprometimento, observa-se que se realiza a busca de parceria com os mesmos fornecedores, mas estão sempre abertos a novos parceiros desde que trabalhem com responsabilidade. O comprometimento entre os membros da cadeia é demonstrado, em especial, pelo cumprimento do contrato firmado, pelo contato cordial, bem como pela indicação constante do mesmo fornecedor. $\mathrm{Na}$ cadeia 2, em relação ao comprometimento, existe uma busca para se formar parceria, entretanto em função de alguns benefícios, como a participação no sistema de pacotes, comissão, número de evento indicados e descontos.

Para analisar o comprometimento, segundo os entrevistados, é realizada uma avaliação por parte do organizador de eventos, repassada aos seus fornecedores em todos os eventos. Mas encontra-se um Gap nesse quesito, pois na pesquisa com os fornecedores eles relataram que só recebem avaliação quando há problemas no serviço. Segundo Juran (1992) existe uma série de atividade que caracteriza um bom relacionamento, entre elas cita-se, a avaliação da aptidão do fornecedor. Martin (2003) acrescenta, o planejamento de um evento se divide em três fases: o pré-evento, fase de orçamentos e contratações, o trans-evento fase das atividades do dia do evento e o pós-evento, nas quais as avaliações são feitas. Percebe-se que nas duas cadeias estudadas nesta pesquisa, a última fase do planejamento de um evento, citada por Martin (2003), não ocorre com primor. A avaliação somente é feita quando existe um problema identificado, mas torna-se primordial realizá-la em todos os eventos, visando avaliar a aptidão de cada fornecedor, bem como minimizar futuros erros, para assim fortalecer o contato entre os membros da cadeia. 
Revela-se também na pesquisa quando se mede o comprometimento, outro Gap referente ao contato, tanto na cadeia 1 quanto na cadeia 2 , pois eles se encontram praticamente quando têm eventos juntos, geralmente no dia do evento, durante a montagem (outras formas de contato são raras). Este fato consiste em um complicador, devido o contato entre os membros de um canal ser de extrema importância, pois é a oportunidade de realizarem um planejamento conjunto como destaca Juran (1992). Por ser assim Ferreira e Sganzerlla (2000) também confirmam a importância do contato entre os membros do canal quando afirmam que o marketing de relacionamento se apoia na interação existente em todos os serviços prestados aos clientes, por que sem esse contato a interação se torna fraca ou inexistente.

A pesquisa com a cadeia de suprimentos 1, apresenta a existência da preocupação do cliente com o relacionamento dos membros do canal, vez que eles buscam referências e informações com alguns profissionais, em especial o organizador de eventos. Mas na cadeia 2, os entrevistados não conseguem perceber esse interesse por parte do cliente, talvez por trabalharem pelo sistema de pacotes no qual o cliente não tem contato com os membros da cadeia. No setor de eventos a satisfação do cliente final só será efetivada mediante a qualidade em cada etapa do processo de produção do evento. Portanto torna-se importante os fornecedores da cadeia de suprimentos perceberem que o cliente, por meio de seu interesse em colher informações, de certa forma, avalia o contato entre os membros do canal, medindo mesmo que indiretamente o relacionamento existente.

Em relação à confiança, as cadeias estudadas apresentam alguns quesitos que demonstram indícios como: tentar manter os mesmos fornecedores e só indicar quando já trabalharam algum tempo. Mas a confiança ultrapassa esses pontos. Segundo apresenta Claro (2004), confiança pode ser entendida como segurança que o parceiro realizará aquilo que se deseja em vez do que se teme. $\mathrm{O}$ autor acrescenta ainda que o comportamento, o caráter, a personalidade, os princípios e os valores dos indivíduos envolvidos no relacionamento afetam a confiança.

$\mathrm{Na}$ cadeia 1 observa-se que tanto o organizador quanto os fornecedores entrevistados percebem a importância da supervisão dos serviços, mesmo quando existe confiança entre eles, colocando a supervisão como um fator rotineiro no trabalho de eventos. Por isso apontase também o organizador de eventos como a pessoa ideal para exercer a função de supervisor. 
A cadeia 2, em relação à confiança, apresenta alguns pontos diferentes, nos quais a supervisão, para a maioria da cadeia, não se faz necessária em todos os eventos. A maioria também compreende que a supervisão é uma forma de desconfiança, isso reflete então na falta de conhecimento em relação às minúcias que compõem o setor de serviços em eventos no qual as atividades não podem ser corrigidas ou refeitas na hora do evento, pois o "produto" é consumido na hora. Surge então a relevância de se estabelecer padrões mínimos, os quais garantam o sucesso, ressalta Zeithaml e Bitner (2003). Portanto, em função de se trabalhar com serviços prestados por seres humanos, a supervisão se torna necessária para manter a qualidade e o padrão solicitado pelo cliente.

A confiança também se estabelece pela troca de informações, como retrata Novais (2007). Cada elo da cadeia de suprimentos interage com outros elos da cadeia, confirmando a importância da informação e do relacionamento entre os componentes. Quanto ao repasse de informações e o contato, verifica-se que acontece com maior veemência entre o cliente contratante com o organizador de eventos, bem como entre o organizador de eventos e alguns fornecedores. Mas observa-se se raro a troca de informações o contato entre as empresas fornecedoras, mesmo diante da dependência entre as funções desempenhadas por eles.

Os entrevistados relataram que as reuniões são esporádicas, acontecendo somente em eventos de grande complexidade. A confiança deve existir entre todos os membros da cadeia de suprimentos, em especial entre o profissional, eleito como líder e os outros. A pesquisa revela que, para as duas cadeias estudadas o organizador de eventos é considerado o comandante da cadeia, pois a ele cabe a função de administrar todas as etapas de execução de um evento, bem como fazer o elo entre o cliente e os fornecedores. Esse dado comunga com Rangar (2008), para o teórico comando significa orientar, mas também conduzir constantemente mudanças no planejamento e na administração do canal, a fim de alinhá-lo às necessidades dos clientes.

No quesito troca de informações, as duas cadeias pesquisadas se assemelham, pois todos relatam saber da importância da comunicação para o segmento de eventos, em especial pela ligação existente entre os serviços. Mas como demonstrado na categoria confiança, essas informações são repassadas em sua maioria por e-mail, telefone e dificilmente por reuniões. Já ás informações referentes ao desempenho de cada profissional, as chamadas avaliações, são feitas em alguns momentos durante o evento, às vezes após o evento. Ciente que essa 
informação sobre o desempenho se concentra na opinião do organizador de eventos e do cliente contratante (não existe uma avaliação efetiva para os clientes participantes).

Percebe-se que referente à troca de informações, o relacionamento não acontece de forma efetiva, mas em partes, o que contradiz o argumento de Novais (2007), pois para ele toda cadeia de suprimentos, seja de produtos ou de serviços, deve garantir um fluxo de informações rápidas e precisas entre os elementos participantes. Ferreira e Sganzerlla (2000), também destacam que o marketing de relacionamento se apoia na interação existente em todos os serviços prestados ao cliente. A interação se faz também por uma eficiente comunicação, um dinâmico e contínuo fluxo de informações tanto sobre as questões técnicas do evento e as informações relacionadas ao desempenho sobre a satisfação dos clientes.

$\mathrm{Na}$ categoria dependência do fornecedor a cadeia de suprimentos 1, indica ter consciência da dependência existente entre os serviços, pois um fornecedor precisa do serviço do outro para iniciar ou concluir o seu. Foram relatadas histórias as quais demonstram essa dependência, mas também os problemas que acontecem quando há desencontros, em especial por falta de comunicação e falta de um eficiente fluxo de informação como relatado na categoria acima. Mas mesmo assim não existem ações efetivas para minimizar os transtornos que essas dependências podem causar.

Na categoria dependência do fornecedor a cadeia de suprimentos 2, apresenta dependência ainda maior que a cadeia 1, porque trabalha com o sistema de pacote, no qual o organizador de eventos é responsável por tudo. Mas apesar de se mostrarem conhecedores dessa dependência não tem ações efetivas para minimizar os impactos causados por ela. Os respondentes até relatam que contam com o fator sorte, dizendo que tudo se resolve na hora e no final tudo sai corretamente. Mas essa não é a visão do cliente, como será apresentado na entrevista com os clientes contratantes e participantes. Assegura Ganesan (1994), dependência é a necessidade que uma das partes tem de manter a relação com a outra para alcançar metas desejadas. Percebe-se que os entrevistados têm consciência dessa dependência, mas não a trabalham no sentido de atingirem em conjunto a meta traçada pelo cliente, devido enxergarem apenas os problemas que a dependência traz. 
Em relação à dependência, no sentido da dificuldade para encontrar fornecedores, mas também ter de permanecer com eles por falta de opção, os entrevistados acrescentam que não existe, pela facilidade de entrada no setor. A abertura de empresas que trabalham com eventos é constante, isso até atrapalha um pouco no que tange à dificuldade no relacionamento, em função de trabalharem com cadeias diferentes a cada evento. Compreende-se por meio desses relatos que a cadeia de suprimentos do setor de eventos se encaixa dentro dos padrões de dois tipos de canal descritos por Novais (2007). O canal híbrido, no qual o elemento da cadeia de suprimento que tem relacionamento direto com cliente não é mais responsável por executar todas as funções do canal, então torna-se necessário grande transparência na troca de informações e parcerias duradouras. Por ser assim acrescenta-se com Novais um dos problemas dos canais híbridos é que alguns membros da cadeia trabalham para outros canais concorrentes. Dado pertinente com a pesquisa, pois no setor de eventos nem sempre se trabalha com a mesma cadeia de suprimento, devido os fornecedores trabalharem com outros concorrentes. Outro canal, referido por Novais, aplicado ao setor de eventos é o múltiplo. Esse tem como principal característica a utilização de mais de um canal de distribuição em função da diversidade de tipos de consumidor. Nesta área os consumidores têm enorme variação desde religião, estilo, classe social, cultura, assim tudo isso influencia no trabalho e na escolha dos fornecedores para a realização do evento. Novais (2007), ainda ressalta que a grande preocupação nesse tipo de canal consiste na dificuldade em fidelizar o cliente.

Quanto ao investimento no relacionamento, nas duas cadeias estudadas os entrevistados apontam a indicação de clientes, cortesias, brindes, descontos como formas de investimento no relacionamento, isto é, ações mais ligadas a área comercial. Avalia-se então, para os pesquisados o relacionamento se mede mais pelos benefícios financeiros. Segundo os entrevistados a maior dificuldade em se manter parceria é a facilidade de novos entrantes, por isso nem sempre trabalham com a mesma cadeia. $\mathrm{O}$ individualismo prevalece, pois a maioria não consegue enxergar a cadeia de suprimentos como um todo, mas ressalta-se que esse termo não é conhecido e nem utilizado pelos profissionais de eventos.

Apesar do pouco investimento no relacionamento, os entrevistados reconhecem a importância de se formar parceria, como também compreendem que o maior retorno consiste na satisfação do cliente. Todavia, segundo eles, pouco se tem feito em prol da união da categoria, para 
efetivamente gerar melhor relacionamento. Confirma-se isso, pois sabe-se que não existe nenhum órgão representativo para os profissionais de eventos sociais em Goiânia.

Verifica-se dentro desse contexto da entrevista, que as cadeias têm discrepância em alguns assuntos, mas em outros encontram semelhança nas respostas. Portanto analisa-se que o grau de relacionamento existente nesse segmento é baixo, diante do contato superficial existente entre os membros, há falta de ações voltadas para a parceria e falta de preocupação com todos os envolvidos no processo de realização de um evento. Madruga (2004) afirma que o relacionamento é uma maneira sofisticada de interagir com os clientes e parceiros, o qual por sua vez permite a empresa satisfazer as necessidades dos clientes além de seus fornecedores, agregando valor aos produtos e serviços.

Percebe-se que a cadeia de suprimentos do setor de eventos apresenta alguns Gaps em seus sistemas de atuação, em especial em relação a comunicação, a avaliação dos serviços, a percepção de qualidade e visão sistêmica dos serviços, fatores esses complementares para um bom relacionamento. Por tanto o marketing utilizado pelas empresas se enquadra mais no de transação do que no de relacionamento. Como apresenta Claro (2004), o marketing de transação é composto por comunicação mais impessoal, clima suspeito, informações vagas, dispersas e mais orientadas para o preço, investimento baixo em relacionamento e confiança entre as partes baixa. O quadro 4 apresenta as principais considerações referentes a cada cadeia estudada.

\section{Quadro 4: Categorias x Cadeias Estudadas}

\begin{tabular}{|c|c|c|}
\hline Categoria & Cadeia de suprimentos 1 & Cadeia de suprimentos 2 \\
\hline Comprometimento & $\begin{array}{l}\text { Busca parceria com os mesmos } \\
\text { fornecedores, mas sem conotação de } \\
\text { exclusividade. O comprometimento entre } \\
\text { os membros da cadeia é demonstrado em } \\
\text { especial pelo cumprimento do contrato } \\
\text { firmado, pelo contato cordial, bem como } \\
\text { pela indicação constante do mesmo } \\
\text { fornecedor. }\end{array}$ & $\begin{array}{l}\text { Busca de parceria, Mas com fornecedores } \\
\text { que trabalham pelo sistema de "pacotes". o } \\
\text { comprometimento é demonstrado pela } \\
\text { busca para se formar parceria, em função de } \\
\text { alguns benefícios como a participação no } \\
\text { sistema de pacotes, comissão, número de } \\
\text { evento indicados e descontos. }\end{array}$ \\
\hline
\end{tabular}




\begin{tabular}{|c|c|c|}
\hline Confiança & $\begin{array}{l}\text { Os entrevistados percebem a importância } \\
\text { da supervisão dos serviços, mesmo } \\
\text { quando existe confiança entre eles. } \\
\text { A confiança para indicar uma empresa ao } \\
\text { cliente só existe após efetuarem um } \\
\text { número relativo de eventos juntos. }\end{array}$ & $\begin{array}{l}\text { Supervisão é sinal de desconfiança, não } \\
\text { sendo necessária em todos os eventos. } \\
\text { A confiança para indicar um fornecedor } \\
\text { vem da amizade, do estilo de trabalho e do } \\
\text { preço que o fornecedor cobra. }\end{array}$ \\
\hline $\begin{array}{l}\text { Troca de } \\
\text { informações }\end{array}$ & $\begin{array}{l}\text { No quesito troca de informações, relatam } \\
\text { saber da importância da comunicação } \\
\text { para o segmento de eventos, em especial } \\
\text { pela ligação existente entre os serviços. } \\
\text { Mas, essas informações são repassadas } \\
\text { em sua maioria por e-mail e telefone e } \\
\text { dificilmente por reuniões. }\end{array}$ & $\begin{array}{l}\text { No quesito troca de informações, relatam } \\
\text { saber da importância da comunicação para } \\
\text { o segmento de eventos, em especial pela } \\
\text { ligação existente entre os serviços. Mas, } \\
\text { essas informações são repassadas em sua } \\
\text { maioria por e-mail e telefone e dificilmente } \\
\text { por reuniões. }\end{array}$ \\
\hline $\begin{array}{l}\text { Dependência do } \\
\text { fornecedor }\end{array}$ & $\begin{array}{l}\text { Sabem da dependência existente entre os } \\
\text { serviços, em que um fornecedor precisa } \\
\text { do serviço do outro para iniciar ou } \\
\text { concluir o seu. Foram relatadas histórias } \\
\text { que demonstram essa dependência e } \\
\text { também os problemas que acontecem } \\
\text { quando há desencontros, em especial por } \\
\text { falta de comunicação e falta de um } \\
\text { eficiente fluxo de informação. }\end{array}$ & $\begin{array}{l}\text { Existe grande dependência dos } \\
\text { fornecedores, pois trabalham com o sistema } \\
\text { de pacote, no qual o organizador de eventos } \\
\text { é responsável por tudo. Mas apesar de se } \\
\text { mostrarem conhecedores dessa dependência } \\
\text { não tem ações efetivas para minimizar os } \\
\text { impactos causados por ela. Até relatam } \\
\text { contar com a sorte, dizendo que tudo se } \\
\text { resolve na hora. }\end{array}$ \\
\hline $\begin{array}{l}\text { Investimento no } \\
\text { relacionamento }\end{array}$ & $\begin{array}{l}\text { O investimento no relacionamento é } \\
\text { realizado por meio da indicação de } \\
\text { clientes, cortesias, brindes e descontos. } \\
\text { Ações mais ligadas à área comercial. }\end{array}$ & $\begin{array}{l}\text { O investimento no relacionamento é } \\
\text { realizado por meio da indicação de clientes, } \\
\text { cortesias, brindes e descontos. Ações mais } \\
\text { ligadas a área comercial. }\end{array}$ \\
\hline
\end{tabular}

Fonte: autora

\subsection{Análise das entrevistas com os clientes}

Em relação aos dados obtidos em entrevista com os clientes, verifica-se que as respostas da cliente contratante da cadeia 1 e da cliente contratante da cadeia 2 , se assemelham em muitos pontos, em especial, em relação à expectativa e à qualidade. Existe diferença quanto ao nível 
social, à preferência, aos profissionais contratados e ao próprio evento. Apesar de se enquadrarem na mesma tipologia, eventos sociais, os casamentos apresentam diferença nos quesitos organização, decoração, alimentos e bebidas e espaço para festa. A cliente contratante 1 realizou um evento com mais luxo do que a cliente contratante 2. Esse dado reforça que a cadeia de suprimentos de eventos pode se enquadrar no tipo de canal múltiplo no qual Novais (2007), ressalta a diversidade de tipos de consumidor.

Em relação à expectativa, as clientes contratantes entrevistadas têm como expectativa maior a opinião dos convidados e a execução correta de todos os serviços contratados, para não ocorrer problemas. Enfim, esperam que o evento aconteça como foi sonhado por elas. Para os clientes participantes, as expectativas estão relacionadas mais com a decoração do evento, com a organização, em especial com a área de alimentos e bebidas. Percebe-se a importância em se levantar as expectativas dos clientes, pois se torna difícil para os profissionais de eventos avaliarem a satisfação de seus clientes sem antes levantarem as expectativas deles. Destacam Hamel e Prahalad (1990), deve-se ir além de simplesmente perguntar aos clientes/usuários o que eles desejam, deve-se explorar: necessidades declaradas; necessidades reais; necessidades não declaradas; necessidades de "algo mais"; necessidades "secretas".

As expectativas se diferem para os dois públicos. Para os clientes contratantes qualidade consiste no cumprimento do contrato, a criatividade, mas também o conhecimento de cada profissional. Já para os clientes participantes, qualidade em um evento é quando existe um bom serviço de alimentos e bebidas, quando a decoração está criativa e o evento bem organizado. Um dos pontos para analisar o que gera valor ao cliente esta em identificar os principais atributos que merecem valor para o cliente e a melhor forma de identificar essas características é perguntando ao próprio cliente a sua opinião.

Quanto à busca de informações sobre os profissionais do setor de eventos, como um tipo de referência, a cliente contratante 1 apresenta preocupação em saber informações sobre cada profissional ou empresa contratada enquanto a cliente contratante 2 se ateve mais ao preço que cada profissional cobrava.

O valor percebido segundo Sinhá \& De Sarbo (1998), é uma construção multidimensional derivada de várias percepções dentre elas os benefícios que o cliente tem com aquisição ou 
uso de determinado produto ou serviço. Dessa forma, torna-se importante saber que tipo de benefício os clientes esperam ter com a realização do evento. Foram apresentados na pesquisa benefícios intangíveis, como: os comentários positivos dos convidados e as boas lembranças, isso demonstra novamente a preocupação dos clientes contratantes com a opinião dos convidados.

A pesquisa aponta que as informações e os contatos entre os membros da cadeia de suprimentos do setor de eventos norteiam apenas os fornecedores, os quais têm contato direto com o cliente, pois as clientes contratantes não têm informações ou contato com a cadeia secundária (fornecedores de matéria-prima). Elas não sabem de onde vem os produtos e quem são essas outras empresas, isso parece indiferente para elas. Por ser assim esclarecem Vavra (1993), Bretzke (2000) e Berry (1995), o marketing de relacionamento deve considerar todos os relacionamentos que possam influenciar a satisfação do cliente.

A satisfação só existe quando não ocorrem problemas graves e quando os convidados saem satisfeitos. Para os convidados, satisfação é serem bem recepcionados, com um lugar para sentarem-se com suas famílias, terem comida de boa qualidade, farta, animação e organização. Alguns clientes participantes têm noção de que para realizar um evento necessita-se a contratação de inúmeros profissionais de empresas diferentes, mas mesmo assim quando algo acontece de errado atribuem a falha ao organizador de eventos. Isso demonstra um dado importante, os clientes participantes não enxergam a cadeia de suprimentos, não conseguem separar os inúmeros profissionais atuantes na execução de um único evento.

As considerações acima demonstram a percepção dos clientes em relação ao valor. O que gera valor para o cliente contratante de um evento social em primeiro lugar é a satisfação do cliente participante. Os entrevistados também obtêm satisfação em outros pontos, como: a qualidade dos alimentos e bebidas, com a receptividade, com a ambientação do local e um som de qualidade. Mesmo não se mostrando conhecedor dos diferentes serviços, observa-se que o cliente valoriza pontos diversos do evento, isso remete à reflexão de que no setor de eventos a satisfação do cliente final só será efetivada mediante a excelência em cada etapa do processo de produção do evento. Como se trata de prestação de serviço essa qualidade ainda é 
mais difícil de ser percebida e mesurada, surge assim, a importância de se levantar a expectativa do cliente, visando supri-la, a fim de proporcionar satisfação e valor.

Zeithaml (1998) ressalta poder existir diferenças entre as expectativas dos clientes quanto aos atributos de valor do produto e ou serviço e as percepções da empresa sobre essas expectativas, isso corresponde a um Gap entre o que a empresa entende que o cliente quer e o que o cliente diz querer.

\subsection{Análise da entrevista com os fornecedores da cadeia secundária}

A cadeia secundária que corresponde aos fornecedores de matéria-prima contribui para que o evento, considerado produto final, seja realizado, mas nem todos têm consciência disso. A maioria não sabe como fica o produto final ou nem sabem como o produto fornecido por eles será utilizado. Os fornecedores da cadeia secundária, só se relacionam com o comprador, isto é, quem faz o pedido e nunca tem acesso ao cliente contratante, muito menos aos participantes. Dessa forma, que parece ser indiferente a importância da função deles (cadeia secundária) para o evento.

\subsection{Análise geral de todos os dados coletados}

Dentre os dados coletados verifica-se que, em relação ao relacionamento, a cadeia de suprimentos do setor de eventos de Goiânia ainda precisa de alguns ajustes. As informações coletadas em entrevista apontam alguns fatores deficientes, os quais se confirmam quando comparados aos pensamentos de Juran (1992), pois o teorico afirma existir uma série de atividades que devem ser seguidas em prol de um bom relacionamento, sendo a primeira: o planejamento pré-contrato. Entretanto, vislumbra-se nas cadeias estudadas ser raro, devido a troca de informações se realizar somente perto do evento, e não alcançar toda a cadeia de suprimentos, ficando restrita a alguns profissionais.

A segunda atividade elencada por Juran (1992) consiste na avaliação da aptidão do fornecedor. A pesquisa revela que as avaliações são realizadas, em geral, apenas quando tem problemas, não tendo um sistema organizado de avaliar. $\mathrm{O}$ autor cita outra atividade, a seleção do fornecedor. Nas cadeias estudadas não existe um padrão de escolha desses fornecedores, até pela grande opção existente no mercado. Geralmente são escolhidos pelo vínculo de amizade, pela indicação de terceiros ou por aderirem ao pagamento de comissões. 
A quarta atividade apresentada pelo autor consiste no planejamento conjunto. Por ser um setor aberto a novos entrantes a cadeia apresenta uma parcela de profissionais amadores, que geralmente não se reúnem e se comunicam apenas quando necessário. Não trabalham a visão sistêmica, por isso o planejamento conjunto é raro. Apesar de reconhecerem a dependência existente entre cada serviço, a pesquisa revela um dado importante, os fornecedores pensam mais isoladamente em cada serviço, enquanto o cliente pensa no evento como um todo.

Por último Juran (1992) institui a cooperação com o fornecedor durante a execução do contrato. A cooperação é baixa, em função da falta de uma comunicação efetiva entre os participantes da cadeia. Apesar de reconhecerem a figura do organizador de eventos como um líder da cadeia, a presença e a supervisão dele aparece mais como um apaziguador de conflitos, do que de um gerente estratégico. Outro ponto deficiente encontrado nas cadeias estudadas, o qual confirma a falta de um relacionamento eficiente, concentra-se na percepção de qualidade e satisfação serem diferentes para o organizador, para fornecedores e para clientes. Enquanto os fornecedores se preocupam em fazer o evento como foi solicitado, por compreender que esse fator gera satisfação ao cliente, o cliente contratante tem outra visão, a de que cumprir o contrato é importante, mas também uma obrigação. A satisfação dele está relacionada mais com a satisfação do cliente participante, isso por sua vez passa despercebida na visão dos fornecedores, pois nenhum dos entrevistados tem ações para avaliar ou recolher a opinião do cliente participante. Os entrevistados consideram qualidade o fato de cumprirem com o contrato o que na verdade é obrigação de todo profissional.

Por meio dos dados coletados em entrevistas e das análises realizadas levantam-se alguns gargalos, como: falha na comunicação e na troca de informações, falta de estratégias de avaliação dos fornecedores, falta de estratégias que trabalhem a dependência existente em cada serviço, abertura para novos entrantes, falta de um planejamento conjunto, falta de um melhor gerenciamento da cadeia de suprimentos, falta de reconhecer o cliente participante como membro da cadeia de suprimentos. 


\section{Considerações Finais}

Cadeia de suprimentos e marketing de relacionamento são temáticas pouco estudadas no setor de serviços em eventos. Esses termos não são utilizados, nem tão pouco conhecidos entre a maioria dos profissionais. Percebe-se, entretanto que o relacionamento eficiente pode contribuir para minimizar os problemas encontrados na montagem do evento, bem como durante seu acontecimento, mas também poderá contribuir para o crescimento de cada fornecedor em relação ao conhecimento e à parceria. Além de tornar o setor mais fechado para novos entrantes, esses benefícios, se transmitidos para o cliente de forma correta, vão propiciar mais credibilidade e consequentemente agregarão mais valor.

Diante dos dados coletados e após análise verifica-se, que existem mais transações comerciais e menos relacionamento na cadeira de suprimentos do setor de eventos. Esse relacionamento somente irá se tornar valoroso para o cliente quando existir uma visão sistêmica por parte de toda a cadeia e quando utilizarem isso como um fator para proporcionar credibilidade na hora em que o cliente estiver selecionando profissionais, por ser um segmento no qual existe uma gama variada de profissionais e com preços discrepantes.

Recomenda-se que o marketing de relacionamento, no contexto do setor de serviços em eventos, seja aprofundado em pesquisas quantitativas e qualitativas, a fim de que seja possível analisar também os outros atores envolvidos. A ampliação da discussão poderá ser útil para construção de mais modelos de marketing de relacionamento no setor de serviços, visando o crescimento e o envolvimento cada vez maior entre empresas, clientes e fornecedores.

\section{Referências}

ALBRECHT, K. \& BRADFORD, L.J. Serviços com qualidade: a vantagem competitiva. São Paulo, Makron Books, 1992.

BERRY, L. Relationship marketing of service: growing interest emerging perspectives. Journals of Academy of Marketing Science, v. 23, n. 4, 1995.

BITITCI, Umit. S. and MENDIBIL, Kepa; MARTINEZ, Veronica; ALBORES, Pavel. Measuring and Managing Performance in Extended Enterprises. International Journal of Operations \& Production Management, v. 25, n. 4, p. 333-353, 2005.

CLARO, D. P. Managing business network and buyer-supplier relationship. Universal Press: Veenendal, 2004. 
CARDOSO, O. R. Foco da qualidade total no conceito do produto ampliado. 1995. Tese (Doutorado em Engenharia de Produção) - Programa de Pós-graduação em Engenharia de Produção, Universidade Federal de Santa Catarina, Florianópolis.

COUGHLAN, A. T. et al. Canais de Marketing e Distribuição. 6 ${ }^{\mathrm{a}}$ ed. Porto Alegre: Bookman, 2002.

FERREIRA, Sérgio; SGANZERLLA, Silvana. Conquistando o consumidor: o marketing de relacionamento como vantagem competitiva das empresas. São Paulo: Gente, 2000.

FLEURY, A. \& FLEURY, M.T. Competitive strategies and core competencies: perspectives for the internationalization of industry in Brazil. Integrated Manufacturing Systems, v.14, 2003 p.16-25.

GANESAN, S. Determinants of long-term orientation in buyer-seller relationship. Journal of Marketing, v. 2, n. 58, p. 1-19.

CORRÊA, H. L.; GIANESI, I. G. N. (1996) Just in Time, MRP II e OPT: um enfoque estratégico. Atlas S.A: São Paulo.

GRÖNROOS, Christian. Marketing: gerenciamento e serviços. Rio de Janeiro: Campus, 1991.

HESKETT, James L. Logistics: essential to strategy. Harvard Business Review, n.55, Nov-Dec. 1977.

JURAN J.M. Planejando a qualidade. São Paulo: Pioneira, 1992.

LARENTIS, Fabiano; SLONGO, Luiz Antonio. Relacionamento em canais de marketing como fonte de vantagem competitiva sustentável. R. Adm. São Paulo, v.43, n.3, p.209-223, jul./ago./set. 2008.

MADRUGA, Roberto. Guia de implementação de marketing de relacionamento e CRM. São Paulo: Atlas, 2004.

MARTIN, Wanessa. Manual prático de eventos. São Paulo: Atlas, 2003.

MENTZER, J. T.; DeWITT, W.; KEEBLER, J. S.; MIN, S.; NIX, N. W.; SMITH, C. D.;

ZACHARIA, Z. G. Defining Supply Chain Management. Journal of Business Logistics, v. 22, n. 2, p. 1-25, 2001.

OCHI, Mara Sandra de Jesus Camargo. Marketing de relacionamento. Dissertação (Mestrado) - UniFacef, Franca, 2004.

PIRES, S. I. R. Gestão da Cadeia de Suprimentos (Supply Chain Management) conceitos, estratégias, práticas e casos. São Paulo: Atlas, 2004.

PORTER, Michel E. Vantagem competitiva: criando e sustentando um desempenho superior. Rio de Janeiro: campus, 1989.

RANGAN, V. Kasturi. Transformando sua estratégia de ingresso no mercado: as três disciplinas da gestão de canais. Porto Alegre: Bookman, 2008.

ROCHA, Angela; LUCE, Fernando. Relacionamento entre compradores e vendedores: origens e perspectivas no marketing de relacionamento. RAE - Clássicos, vol.46. 2006.

SINHA, Lindrajit; DE SARBO, Wayne S. de. Na Integrate Approach Toward the Spatial Modeling of perceived customer value. Journal of Marketing Research, v. 35, n. 2, may, 1998.

SLACK, N.; CHAMBERS, S.; JOHNSTON, R. Administração da produção. 2. ed. São Paulo: Atlas, 2002. 
SLONGO, Antônio Luiz; LIBERALI, Guilherme. Marketing de relacionamentos: estudos, casos e proposições de pesquisa. São Paulo: Atlas, 2004.

LUSCH, R. F.; VARGO, S. L. (Eds.). The service-dominant logic of marketing: Dialog, debate, and directions. Armonk, NY: ME Sharpe, 2006.

VARGO, S. L., \& LUSCH, R. F. The four services marketing myths: Remnants from a manufacturing model. Journal of Service Research, 324-335, May 2004.

VAVRA, Terry G. Marketing de relacionamento. São Paulo: Atlas, 1993.

WILSON, E.; VLOSKY, R. Partnering Relationship Activities: Building Theory from Case Study Research. Journal of Business Research, May, 1997.

ZEITHAML, A. Valarie; BITNER, Jo Mary. Marketing de serviços: a empresa com foco no cliente. Trad. Martin Albert Haag e Carlos Alberto Silveira Netto Soares. 2 ed. Porto Alegre: Bookman, 2003.

ICCA. Relatório anual da Associação Internacional de Congressos e Convenções. International Congress and Convention Assocition. disponivel em: http://www.iccaworld.com/ acesso em: novembro 2012

ABEOC - Associação Brasileira de Empresas de Eventos. Disponível em: http://www.abeoc.org.br/ acesso em: novembro 2012

Recebido em: 14/09/2011 ( $1^{\mathrm{a}}$ versão) $10 / 12 / 2012$ ( $2^{\mathrm{a}}$ versão)

Aprovado em: 19/03/2013 